\title{
Settlement Control of Soft Ground using Cement-Ricehusk Stabilization
}

\author{
Chan, C-M. ${ }^{1}$ and Mokhtar, M. ${ }^{2}$
}

\begin{abstract}
Cement is widely used for improvement of soft soils, but financial and environmental concerns are causing genuine concerns to all parties, leading to the quest for alternative and effective stabilizers. Ricehusk is an agricultural waste in Malaysia, commonly disposed of by open burning or dumping in landfills. Considering that the ashes derived from ricehusk are pozzolanic in nature, there is a possibility that a cement-ricehusk mixture could effectively improve soft soils with reduced cement dosage. This study examines the mixture's effectiveness by monitoring the settlement reduction in a clay soil. Standard oedometer tests were carried out on a soft marine clay sample admixed with cement-ricehusk. Test specimens contained 0-10\% cement and $0-5 \%$ of ricehusk respectively, and were left to cure for either seven or 28 days. The stabilized specimens were observed to undergo significant reduction in compressibility, verifying the potential of cement-ricehusk as an alternative soft soil stabilizer.
\end{abstract}

Keywords: Ricehusk, settlement control, soft soil.

\section{Introduction}

In order to erect infrastructure and buildings over soft ground, either specially designed foundation systems or ground improvement works are required. The former is long proven effective, but economic, environmental as well sustainability issues are fast making the approach undesirable. The latter, however, show trends of practitioners seeking alternative materials to the already-established installation methods. This is primarily to address and mitigate the long term negative impact of physical development on all aspects of modern living, i.e. sustainability.

The Deep Mixing Method (DMM), a deep in-situ soil stabilization technique using cement and lime as a stabilizing agent, was developed in Japan and the Scandinavian countries independently in 1970s. Numerous research efforts have been carried out in the area to examine properties of the treated soil, behavior of DMM improved ground under static and dynamic loading conditions, design methods as well as execution techniques [1].

${ }^{1}$ Senior Lecturer/Research Fellow, Research Centre for Soft Soils (RECESS), Faculty of Civil and Environmental Engineering, Universiti Tun Hussein Onn Malaysia (UTHM), 86400 Parit Raja, Batu Pahat, Johor, MALAYSIA. Email: chan@uthm.edu.my

${ }^{2}$ Research Fellow, Research Centre for Soft Soils (RECESS), Faculty of Civil and Environmental Engineering, Universiti Tun Hussein Onn Malaysia (UTHM), 86400 Parit Raja, Batu Pahat, Johor, MALAYSIA. Email: luv_diyha@yahoo.com

Note: Discussion is expected before November, $1^{\text {st }} 2012$, and will be published in the "Civil Engineering Dimension" volume 15, number 1, March 2013.

Received 19 August 2011; revised 19 May 2012; accepted 27 June 2012.
The purposes of introducing stabilizing agents to soft soils can be summarized as strength enhancement, deformation control, increased dynamic stiffness, and remediation of contaminated soils. The advantages of soil stabilization include being economical, flexibility in applications, and minimal production of spoil for disposal [2].

There are many types of stabilizing agents that possess hardening properties, and various studies have been published on the stabilization effects of these stabilizing agents. According to Sing et al. [3], the most important criterion in the selection of suitable stabilizing agents is their capability of achieving the desirable soil stabilizing function. With the appropriate choice of stabilizing agents, soil stabilization by suitable chemical admixture can increase shear strength and bearing capacity, reduce permeability and compressibility, and improve swelling characteristics of soft soils.

In soil stabilization, cement and lime are the two main materials used as stabilizing agents. However these materials have rapidly increased in prices due to the sharp rise in the cost of energy production as well as the raw ingredients. Ordinary Portland cement is chosen as the main stabilizing agent for this study due to its availability in the country. In addition, as suggested by Broms [4], cement is preferable compared to lime for soft soil stabilization in this region, as cement is cheaper and easier to preserve in the hot and humid climate.

Referring to Romano and Rodrigues [5], Portland cement is produced at temperatures around $1500^{\circ} \mathrm{C}$, where raw materials such as calcium carbonates are 
thermally decomposed, generating considerable amounts of carbon dioxide $\left(\mathrm{CO}_{2}\right)$. Indeed, the production of $1000 \mathrm{~kg}$ of cement requires $100 \mathrm{~kg}$ of fossil fuel and generates $1000 \mathrm{~kg}$ of $\mathrm{CO}_{2}$. Therefore, replacing portions of Portland cement in soil stabilization with a potentially 'cementitious' or 'reinforcing' material like ricehusk $(\mathrm{RH})$ can help reducing the overall environmental impact of the soil stabilization method.

According to Basha et al. [6], as a result of the increase in the amount of solid waste all over the globe, engineers and researchers are obliged to carry out investigations to find useful applications for such wastes. The disposal of the abundant agriculture wastes like RH in Malaysia clearly poses a pressing sustainability and environmental preservation issue. Since open burning is no longer permitted due to environmental concerns [7], various ensuing problems caused by irresponsible disposal of $\mathrm{RH}$ have arisen. This can be avoided by finding suitable engineering applications for its afterlife, such as being used as lightweight backfill materials in geotechnical projects.

Notwithstanding the fact that ricehusk ash (RHA) show desirable bonding potential due to its high of siliceous content, such as demonstrated by Rahman [8] and Muntohar [9-11], there remains a number of undecided fundamental issues, such as quality control of the ash produced, high energy consumption for the conversion process as well uncertain long term environmental impact due to chemical reactions in the ground.
In an effort to reuse the large quantities of $\mathrm{RH}$ as they are, this study was carried out to examine the possibility of combining the waste material with cement for settlement control of soft ground. The cement-RH treated soil, prepared at a range of mix ratios, was subjected to standard laboratory1dimensional compressibility test.

\section{Materials and Methods}

\section{Clay Soil}

The disturbed clay samples were collected from 1-2 $m$ depth of the test site of RECESS (Research Centre for Soft Soils) by using a motorized auger. The clay was dark grey in colour with small contents of organic matter (see Table 1 and Figure 1). The freshly retrieved clay samples were first wrapped with layers of cling film, then tightly bound in plastic bags to prevent moisture loss during transportation and storage. The clay was remolded at its natural water content before being formed into test specimens.

Table 1. Chemical Compositions for Clay, Cement and Ricehusk

\begin{tabular}{llccc}
\hline \multirow{2}{*}{ Chemical composition } & \multicolumn{3}{c}{ Concentration (\%) } \\
\cline { 3 - 5 } & & Clay & Cement & Ricehusk \\
\hline $\mathrm{SiO}_{2}$ & Silica dioxide & 61.40 & 19.00 & 73.30 \\
$\mathrm{~K}_{2} \mathrm{O}$ & Potassium & 2.21 & 0.83 & 6.45 \\
$\mathrm{Fe}_{2} \mathrm{O}_{3}$ & Ferric oxide & 5.22 & 2.58 & 3.74 \\
$\mathrm{SO}_{3}$ & Sulfite & 4.58 & 5.62 & 2.96 \\
$\mathrm{CaO}$ & Calcium oxide & 0.15 & 65.10 & 1.65 \\
$\mathrm{MgO}$ & Magnesium oxide & 1.27 & 1.47 & 1.20 \\
$\mathrm{Al}_{2} \mathrm{O}_{3}$ & Alluminium oxide & 23.80 & 4.68 & 0.84 \\
$\mathrm{CO}_{2}$ & Carbon dioxide & 0.10 & 0.10 & 0.10 \\
$\mathrm{Cl}$ & Chloride & - & - & 1.05 \\
\hline
\end{tabular}

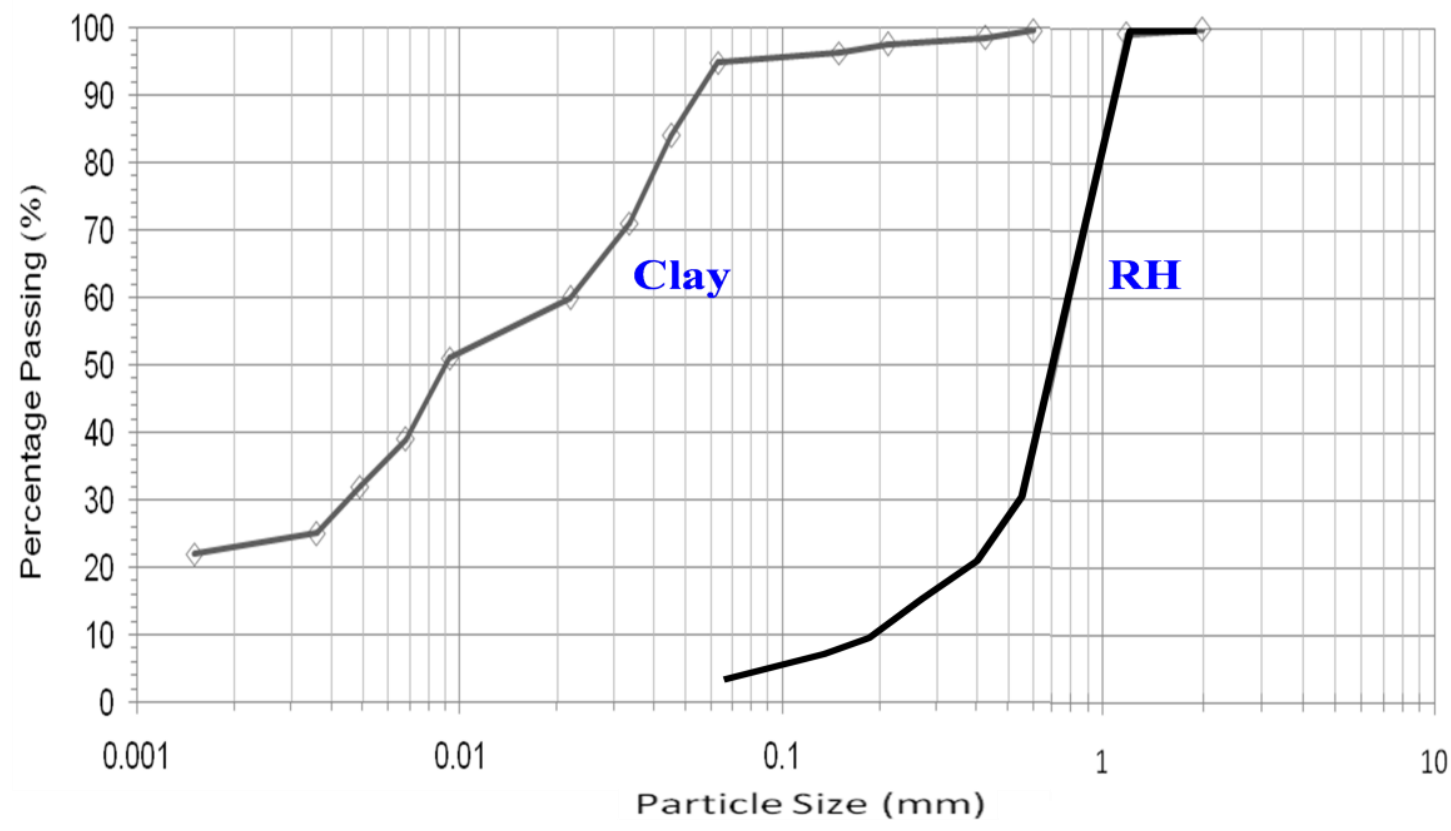

Figure 1. Particle Size Distribution of Clay and RH 


\section{Ordinary Portland Cement}

The ordinary Portland cement (see Table 1 and Figure 2) was first oven-dried at $105^{\circ} \mathrm{C}$ for 24 hours before being stored in airtight containers to maintain the consistency (i.e. removal of entrapped moisture content). Cement was added to the clay in the amount of 0,5 , and $10 \%$, by mass, of the mass of the clay.

\section{Ricehusk (RH)}

Similar with cement, the RH was oven-dried at 105 ${ }^{\circ} \mathrm{C}$ for 24 hours to remove any entrapped moisture (see Table 1, Figures 1 and 2). The dried RH was next ground and sieved, where only portions finer than $425 \mu \mathrm{m}$ were used. The $\mathrm{RH}$ dosage ranged between 0 to $5 \%$ (see Table 2), based on dry mass of the clay soil. These percentages were selected based on Ibrahim's work [12], which focused on the unconfined compressive strength of the same clay soil admixed with $5 \%$ cement and $2-3 \% \mathrm{RH}$. The resulting strengths $\left(\mathrm{qu}_{\mathrm{u}}\right.$ ) were all lower than for the specimen with $5 \%$ cement addition. This was most likely due to the relatively large particle size of $\mathrm{RH}$ used, i.e. $1-4 \mathrm{~mm}$, causing segregation and preferential shear planes within the specimens. Hence the present study adopted the same dosages (and more) but finer $\mathrm{RH}$ particles in an attempt to evaluate the settlement reduction potential of the cement- $\mathrm{RH}$ mix.

Figure 2 shows the physical quantities of various percentages of cement and $\mathrm{RH}$. As clearly shown, the physical amount of $5 \%$ cement (5C) is not much different from that of $2 \% \mathrm{RH}(2 \mathrm{RH})$ due to the lower density of $\mathrm{RH}$ (Gs for cement and $\mathrm{RH}$ are 3.12 and 1.37 respectively). Therefore a seemingly small dosage increment of $0.5 \% \mathrm{RH}$ translates to a significant amount in terms of physical quantity.
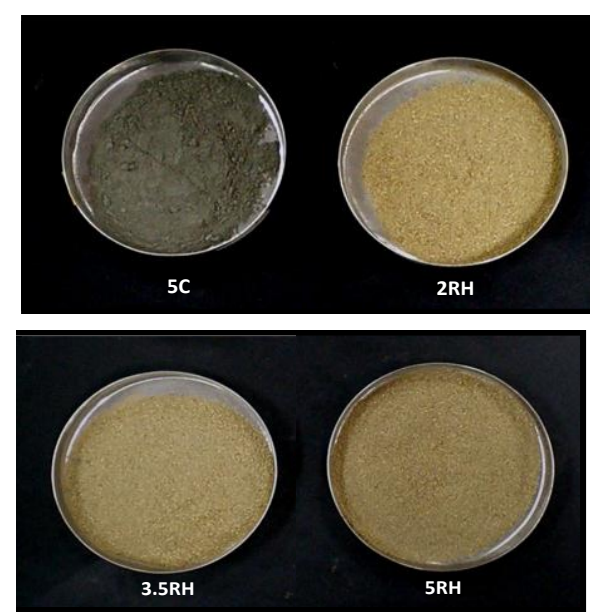

Figure 2. Physical Quantities of Various Percentages of Cement and RH

\section{Preparation of Specimens}

The remolded clay sample was mixed with the required amount of cement and/or $\mathrm{RH}$ at their natural water content. Next, the clay, cement and $\mathrm{RH}$ were thoroughly mixed in a conventional food mixer. To avoid spillage, the food mixer was run at a low speed for the first minute, after which the mixing process was stopped to scrape off the materials stuck on the mixing paddle and sides of the bowl. Mixing was then resumed for another 2-3 minutes, until a homogeneous clay-additive paste was formed. The mixing process took approximately 5 minutes, as recommended in EuroSoilStab [2].

The mixture was compacted in the oedometer ring, measuring $75 \mathrm{~mm}$ in diameter and $20 \mathrm{~mm}$ high, in two layers of $75 \mathrm{~g}$ each. Each layer was tamped and compacted with custom-made miniature compaction tools in the same manner. The top of each compacted layer was scarified before placement of the following layer to improve bonding between the layers. Finally, the specimen was wrapped with cling film and kept in a tightly closed bucket partially filled with a bleach solution, for prevention of fungal growth on the specimen. The specimens were left to cure for seven and 28 days before tests. Details of the test specimens are given in Table 2. Note that the $10 \mathrm{C}$ specimen was meant to serve as a target strength' specimen, for comparison with the cement$\mathrm{RH}$-stabilized specimens, which contained only $5 \%$ cement.

Table 2. Test Specimens: Labels and Descriptions

\begin{tabular}{ll}
\hline \multicolumn{1}{c}{ Specimen } & \multicolumn{1}{c}{ Description } \\
\hline CONTROL & Clay $+0 \%$ cement $+0 \%$ ricehusk \\
$5 \mathrm{C}$ & Clay $+5 \%$ cement \\
$10 \mathrm{C}$ & Clay $+10 \%$ cement \\
$5 \mathrm{C} 2 \mathrm{RH}$ & Clay $+5 \%$ cement $+2 \%$ ricehusk \\
$5 \mathrm{C} 3.5 \mathrm{RH}$ & Clay $+5 \%$ cement $+3.5 \%$ ricehusk \\
$5 \mathrm{C} 5 \mathrm{RH}$ & Clay $+5 \%$ cement $+5 \%$ ricehusk \\
\hline
\end{tabular}

\section{Oedometer Tests}

The oedometer test was carried out based on the procedure given in BS1377: 1990: Part 5 [13]. The specimen was allowed to drain freely from the top and bottom surfaces with the placement of porous discs. Each specimen was loaded up to $1600 \mathrm{kPa}$ before being unloaded following the same sequence in reverse. Each loading and unloading stage was left for 24 hours and the vertical displacements were automatically logged with a PC-based system. Note that consolidation was observed to have completed within the adopted time lapse for all specimens. 


\section{Results Analysis and Discussions}

\section{Nominal 'Zero' of Vertical Stress}

In an oedometer test, the self-weight of the top loading cap should be taken into account as part of the total vertical load acting on the soil specimen [14]. This is especially important for the unstabilized soft clay specimens that tend to deform even under the slightest load imposed. For the present study, the oedometer had a top cap that weighed 388 g, equivalent to a vertical stress of about $8 \mathrm{kPa}$, which was taken as the initial stress at the beginning of all the tests.

\section{Effective Yield Stress}

The apparent consolidation yield stress is roughly equivalent to the pressure at which the stabilized specimen bonds begin to fail during compression [15]. The yield stresses, $\sigma_{y}^{\prime}$, obtained using the regression line $(\mathrm{RL})$ fitting method proposed by Chan [14], is shown in Figure 3. Intersection of the normal consolidation line (NCL) and the initial loading line defines $\sigma_{y}^{\prime}$.

Figure 4 shows a plot of $\sigma_{y}^{\prime}$ against curing time both the unstabilized and stabilized specimens. Note that $\sigma_{\mathrm{y}}^{\prime}$ increased with cement and $\mathrm{RH}$ contents, where $\sigma_{\mathrm{y}}^{\prime}$ is found to be in the range of $58-150 \mathrm{kPa}$. Prolonged curing also increased $\sigma_{\mathrm{y}}^{\prime}$, with higher $\mathrm{RH}$ contributing to the reduced settlement. This strongly indicates the cementatious potential of $\mathrm{RH}$ when used in combination with cement in enhancing the stiffness of an originally soft, weak material. Indeed, it is apparent that $5 \mathrm{C} 5 \mathrm{RH}(28 \mathrm{~d})$ surpassed $10 \mathrm{C}(7 \mathrm{~d})$ in settlement reduction. As such, for field implementation, the same target stiffness can be achieved with the savings of $50 \%$ cement, on condition a 1-month rest period is acceptable.

\section{Compressibility}

Figure 5 and Table 3 give the compression curves and oedometer test results respectively for the 7-day old specimens. The compression curve of the unstabilized soil (CONTROL) is well below those of the stabilized specimens, and generally the vertical strain decreased with increased cement-RH content. This points towards important role cementation plays in reducing the settlement. It was also observed that with increased cement-RH content as well as the curing period, compressibility was markedly improved. Figures 6 to 8 show the compression curves of specimen pairs with the same cement-RH content but different curing periods (i.e. seven and 28 days). The settlement reduction was found to be in the range of $6.9-9.4 \%$. This can be clearly attributed to the presence of $\mathrm{RH}$, where the formation of cementitious gel filled the voids in the specimen, consequently stiffening it with an enhanced structure for load-bearing. This was manifested in the reduced compressibility over time as well as with increased cement-RH dosages.

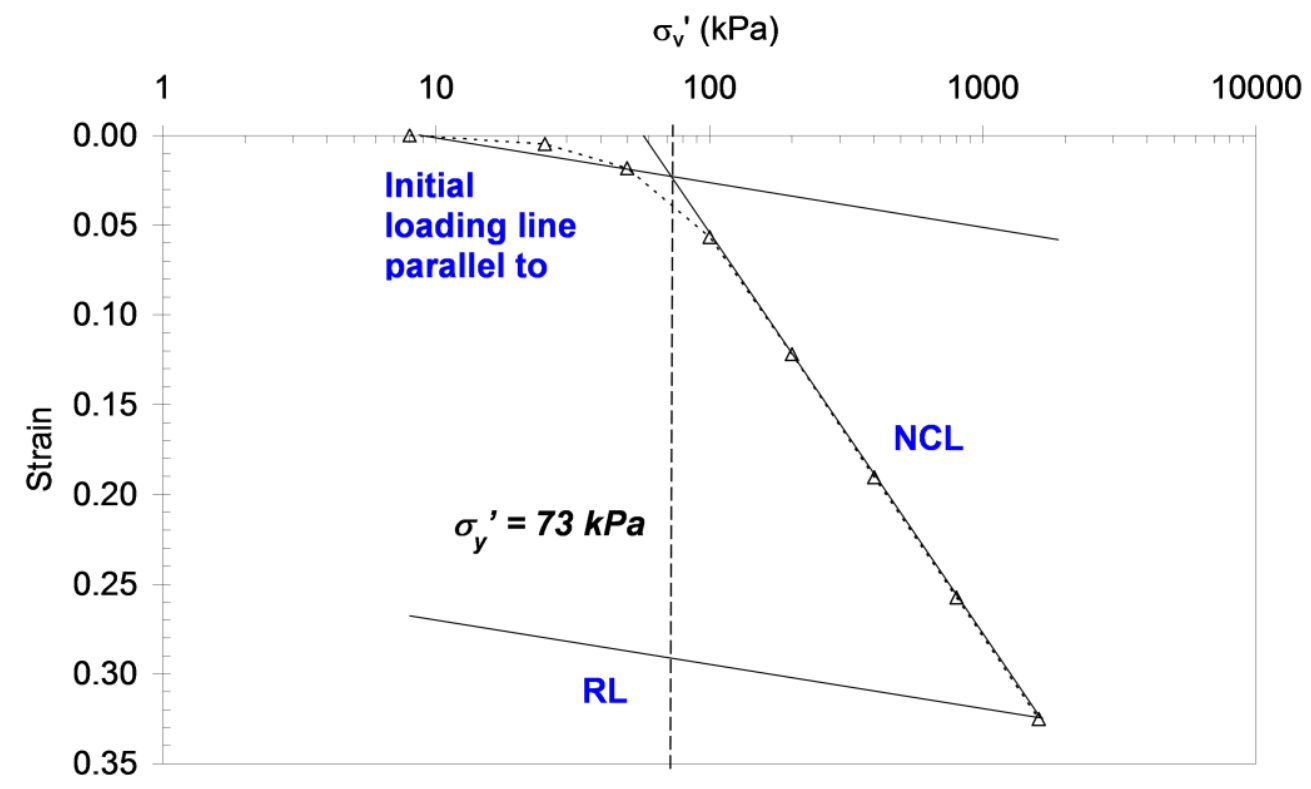

Figure 3. $\sigma_{\mathrm{y}}{ }^{\prime}$ Obtained using the RL Fitting Method 


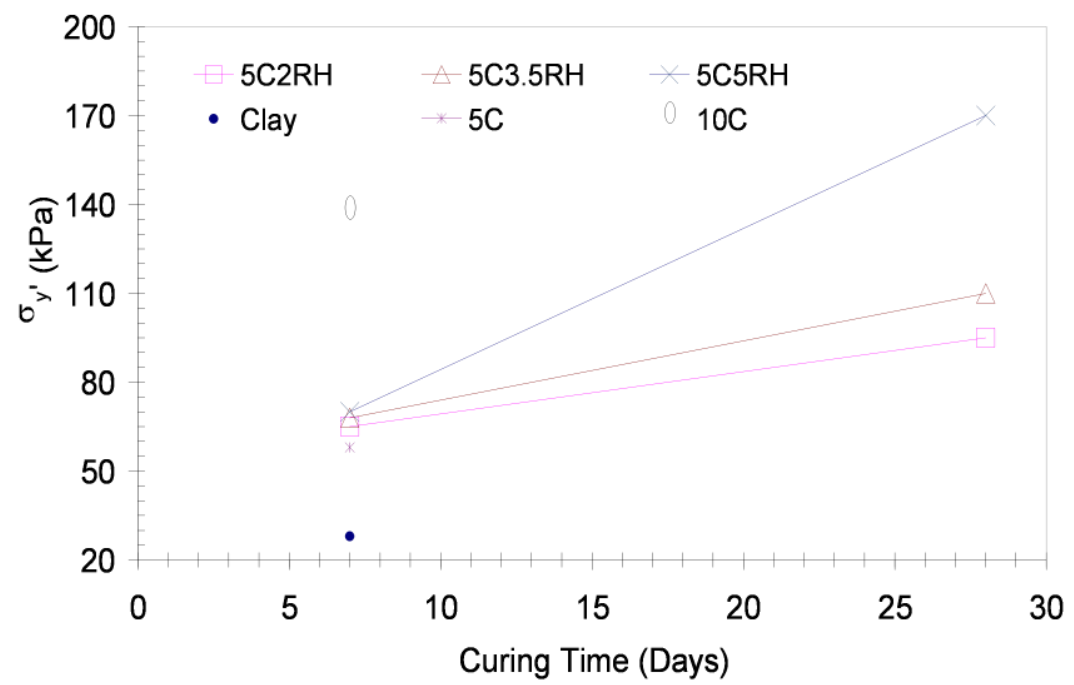

Figure 4. $\sigma_{\mathrm{y}}^{\prime}$ - Curing Time

Table 3. Settlements at Various Effective Stresses (7-day specimens)

\begin{tabular}{cccccc}
\hline \multirow{2}{*}{ Effective stress $(\mathrm{kPa})$} & \multicolumn{5}{c}{ Settlement $(\mathrm{mm})$} \\
\cline { 2 - 5 } & $5 \mathrm{C}$ & $10 \mathrm{C}$ & $5 \mathrm{C} 2 \mathrm{RH}$ & $5 \mathrm{C} 3.5 \mathrm{RH}$ & $5 \mathrm{C} 5 \mathrm{RH}$ \\
\hline 25 & 0.110 & 0.020 & 0.115 & 0.103 & 0.096 \\
50 & 0.799 & 0.027 & 0.674 & 0.545 & 0.365 \\
100 & 1.746 & 0.405 & 1.431 & 1.392 & 1.134 \\
200 & 3.095 & 1.393 & 2.676 & 2.469 & 2.438 \\
400 & 4.530 & 2.700 & 3.924 & 3.877 & 3.808 \\
800 & 5.902 & 4.247 & 5.382 & 5.224 & 5.149 \\
1600 & 7.560 & 5.572 & 6.759 & 6.534 & 6.503 \\
\hline
\end{tabular}

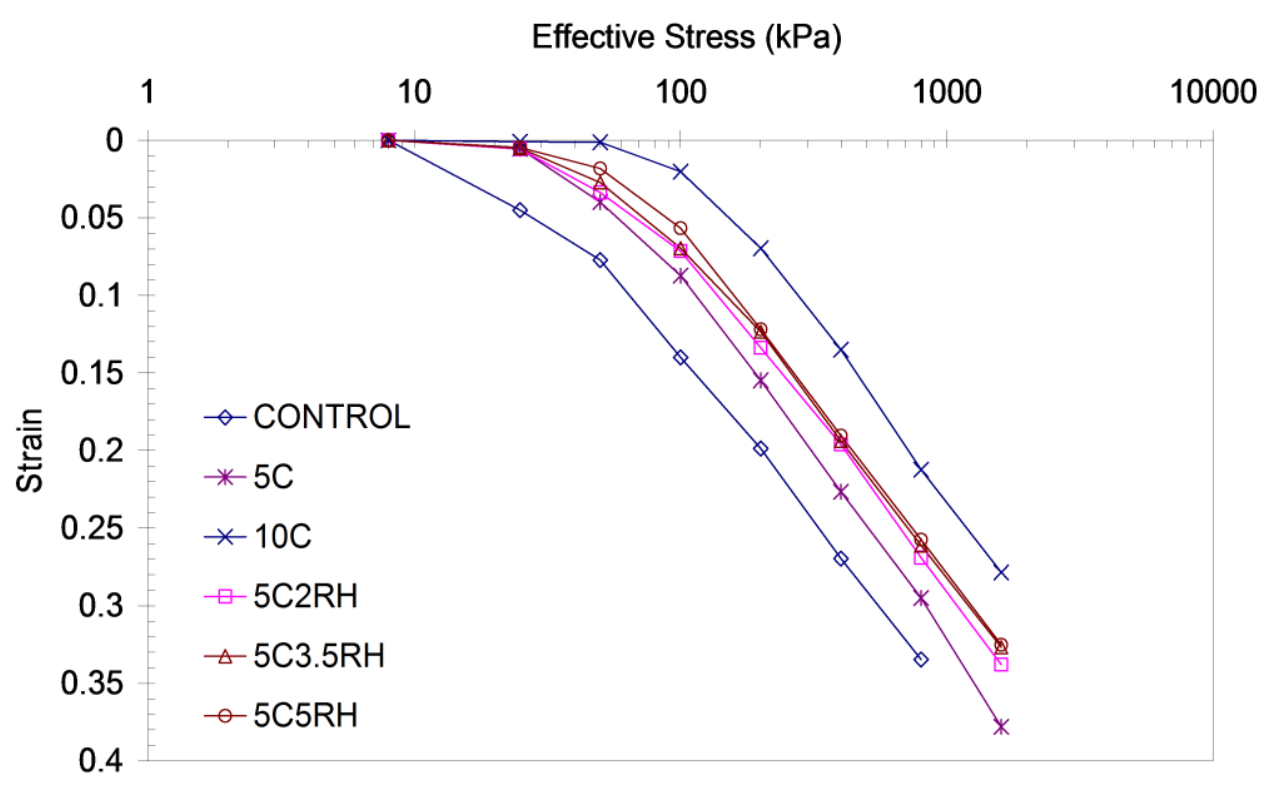

Figure 5. The Compressibility Results for the Oedometer Test (seven days). 


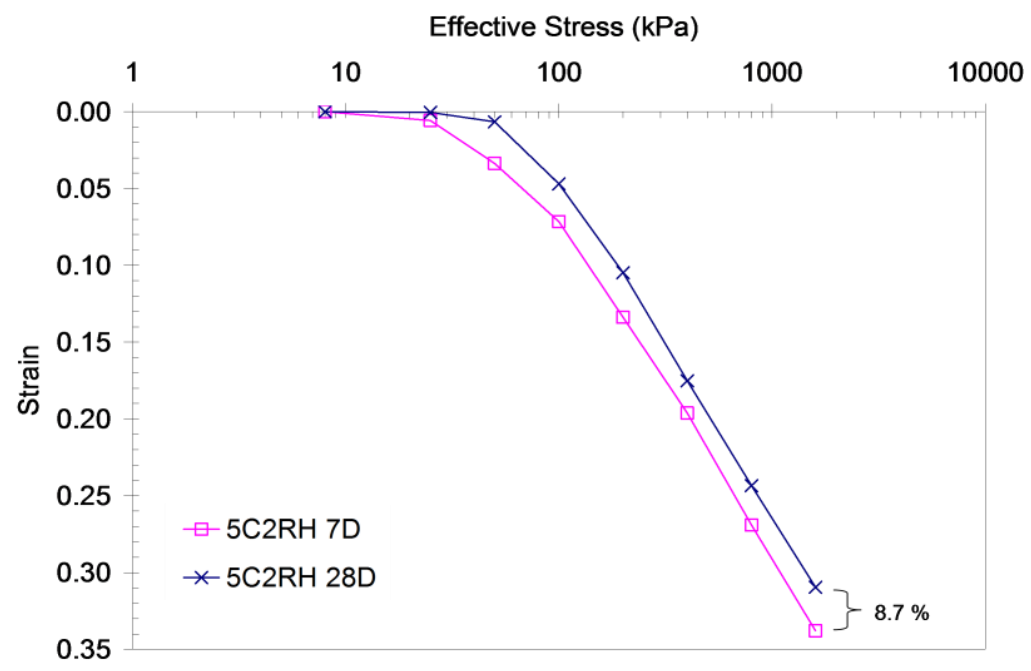

Figure 6. The Compression Curves for 5C2RH at Seven and 28 Days

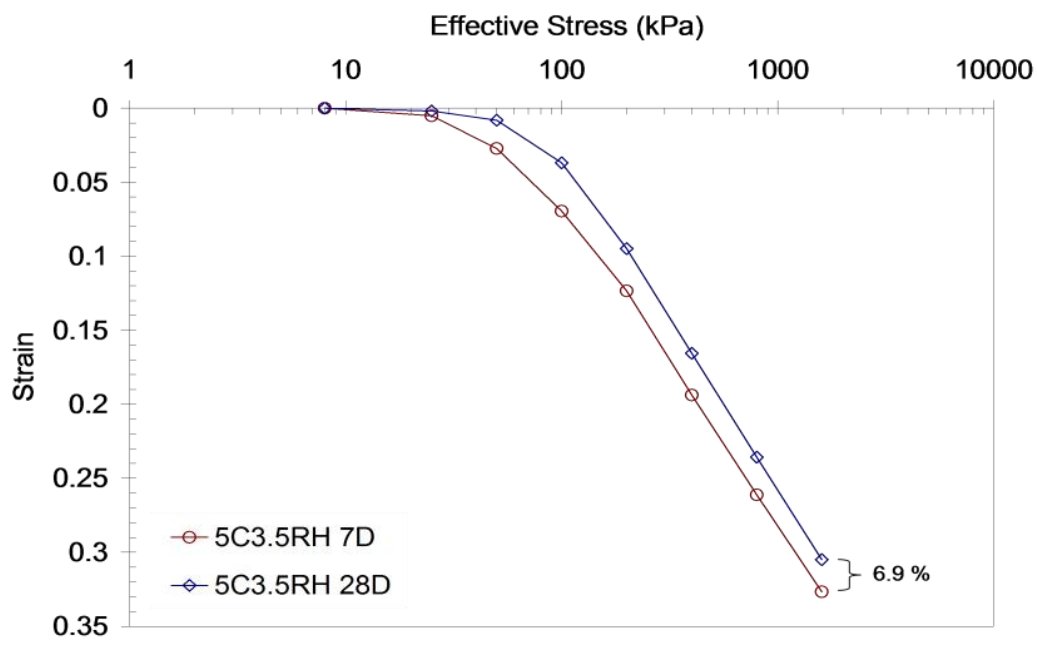

Figure 7. The Compression Curves for 5C3.5RH at Seven and 28 Days

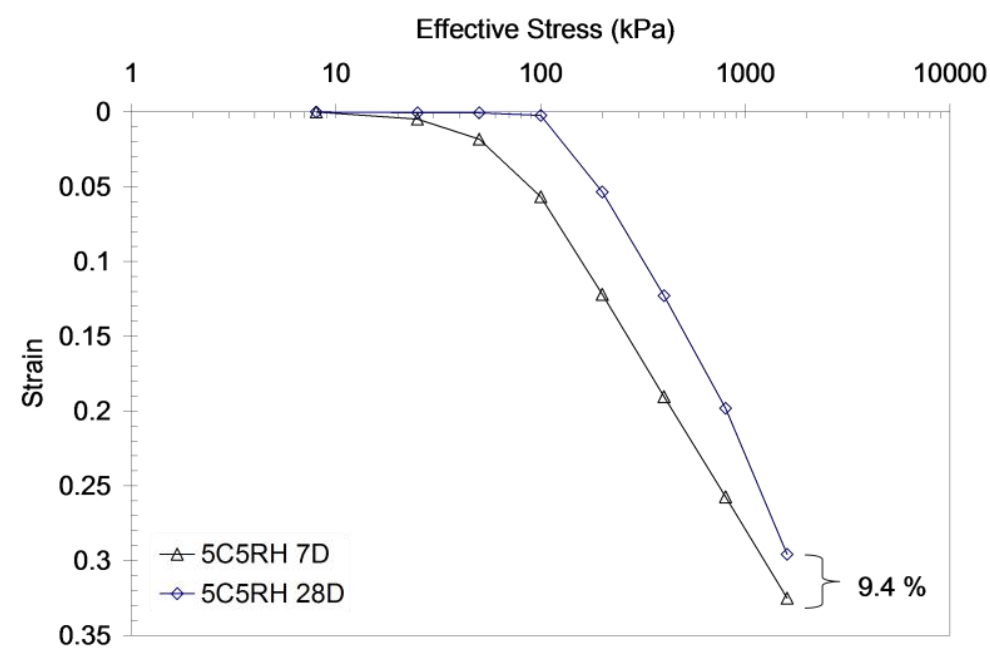

Figure 8. The Compression Curves for 5C5RH at Seven and 28 Days 


\section{Coefficient of Consolidation $\left(c_{v}\right)$}

Determination of $c_{\mathrm{v}}$ is based on two curve fitting methods, namely the logarithm of time (Casagrande) and square root of time (Taylor) methods. Table 4 shows the $c_{v}$ values determined with both methods. As the difference for $c_{v}$ was small, i.e. in the range of 2.1-13.5\%, it is suggestive that the method used for the determination of $\mathrm{c}_{\mathrm{v}}$ did not have a significant effect on the results.

An important effect of soil stabilization with cement is increased $c_{v}$ values [16], Table 4 shows that $c_{v}$ values for the stabilized specimens in the pre-yield region are almost 30 times greater than CONTROL. On the other hand, in the post-yield region, $\mathrm{c}_{\mathrm{v}}$ values of the stabilized specimens are 15-17 times that of CONTROL. This implies effective settlement reduction with the introduction of cement-RH in the clay soil. The positive effect of stabilization with cement$\mathrm{RH}$ agrees well with findings by a number of past researchers [17,18]

\section{Coefficient of Volume Compressibility $\left(\mathrm{m}_{\mathrm{v}}\right)$}

The high value of $\mathrm{m}_{\mathrm{v}}$ underlines the reduction of compressibility of the soil [19]. Table 5 shows the $\mathrm{m}_{\mathrm{v}}$ values for the stabilized and unstabilized specimens at pre- and post-yield regions. Apparently $\mathrm{m}_{\mathrm{v}}$ for the stabilized specimen was lower than that of the CONTROL, again proving that the stabilized specimens were stiffer than the untreated one.

Similar findings were reported by Rao and Shivananda [20], who studied the compressibility of limetreated clay. They found that $\mathrm{m}_{\mathrm{v}}$ decreased with increased lime addition in the clay soils, where the initially soft soil was transformed into a stronger and stiffer material.

Table 4. $c_{v}$ Values for Stabilized Specimen and Unstabilized Clay (7 days)

\begin{tabular}{ccccc}
\hline \multirow{2}{*}{ Specimen } & $\begin{array}{c}\text { Pressure } \\
(\mathrm{kPa})\end{array}$ & $\begin{array}{c}\text { Log Time } \\
(\log \mathrm{t})\end{array}$ & $\begin{array}{c}\text { Root Time } \\
(\mathrm{V} \mathrm{t})\end{array}$ & $\begin{array}{c}\% \\
\text { Difference }\end{array}$ \\
\hline \multirow{2}{*}{ Clay } & 50 & 0.21 & 0.20 & 2.5 \\
& 800 & 0.06 & 0.06 & 2.1 \\
\hline \multirow{2}{*}{$5 \mathrm{C} 5 \mathrm{RH}$} & 50 & 5.85 & 5.11 & 13.5 \\
& 800 & 0.90 & 0.99 & 9.6 \\
\hline
\end{tabular}

Table 5. $m_{v}$ Values for Stabilized Specimen and Unstabilized Clay (7 days)

\begin{tabular}{lcc}
\hline Specimen & Pressure $(\mathrm{kPa})$ & $\mathrm{m}_{\mathrm{v}}\left(\mathrm{m}^{2} / \mathrm{MN}\right)$ \\
\hline \multirow{2}{*}{ Clay } & 50 & 1.35 \\
& 800 & 0.22 \\
\hline \multirow{2}{*}{$5 \mathrm{C} 5 \mathrm{RH}$} & 50 & 0.54 \\
& 800 & 0.21 \\
\hline
\end{tabular}

In general, $\mathrm{m}_{\mathrm{v}}$ values in the pre-yield region were lower than those in the post-yield region. At high $\sigma_{v}^{\prime}$ (e.g. $800 \mathrm{kPa}$ ), regardless of the presence and dosage of cement-RH, the $\mathrm{m}_{\mathrm{v}}$ values tend to converge. This is observed as the compression curves, post-yield, gradually folding into one. A plausible explanation is the gradual deterioration of the cemented structure beyond $\sigma_{\mathrm{y}}^{\prime}$, where the continuously increased stress damages and breaks the cemented bonds. As this 'destructuring' progresses, the treated clay would revert to its normally consolidated condition, i.e. tracing the virgin compression line.

\section{Conclusions}

From the one-dimensional compressibility test, settlement was found to decrease with increased cement$\mathrm{RH}$ content. This exemplified the stiffening effect on the initially soft clay soil. Settlement reduction within the range of $6.9-9.4 \%$ was recorded for specimens with the same cement-RH content but different curing periods, i.e. seven and 28 days. This indicates the positive effect of prolonged curing on the reduced compressibility of cement-RH stabilized soils.

The $c_{v}$ and $m_{v}$ values of the cement-RH specimens were markedly improved in comparison with the original clay specimen, i.e. $96 \%$ increase for $c_{v}$ and $60 \%$ decrease for $\mathrm{m}_{\mathrm{v}}$. This shows effective settlement reduction. It is worth noting that excessive high loads post-yield can lead to 'destructuring' and eventual collapse of the stabilized material, as demonstrated by the significant settlements beyond $\sigma_{\mathrm{y}}^{\prime}$ in the compression curves.

\section{Acknowledgement}

Financial support by the following three respective parties is duly acknowledged: (1) Ministry of Science, Technology and Innovation, Malaysia, (2) Ministry of Higher Education, Malaysia and (3) UTHM's Research and Innovation Centre. The authors also extend their sincere thanks to the management and staff at RECESS, UTHM.

\section{References}

1. Coastal Development Institute of Technology (CDIT), The Deep Mixing Method: Principle, Design and Construction, A.A. Balkema Publishers, Tokyo, 2002.

2. EuroSoilStab, Development of Design and Construction Methods to Stabilize Soft Organic Soils: Design Guide Soft Soil Stabilization, Brussels: CT97-0351, 2002. 
3. Sing, W.L., Hashim, R., and Basha, E.A., Chemical Reactions of Residual Soil Stabilized by Portland Cement and Rice Husk Ash, Proc. of the World Engineering Congress, Malaysia, 2007, pp. 399-407.

4. Broms, B.B., Stabilization of Soft Clay with Lime and Cement Columns in Southeast Asia: Applied Research Project RP10/83, Nanyang Technical Institute, Singapore, 1986.

5. Romano, J.S. and Rodrigues, F.A., Cements Obtained From Rice Hull: Encapsulation of Heavy Metals, Journal of Hazardous Materials, 154, 2008, pp. 1075-1080.

6. Basha, E.A., Hashim, R., Mahmud, H.B. and Muntohar, A.S., Stabilization of Residual Soil with Rice Husk Ash and Cement, Construction and Building Materials, 19, 2005, pp. 448-453.

7. Sarkawi, S.S. and Aziz, Y., Ground Rice Husk as Filler in Rubber Compounding. Jurnal Teknologi (UTM), 39(A), 2003, pp. 135-148.

8. Rahman, M.A., Effect of Cement-rice Husk Ash Mixtures on Geotechnical Properties of Lateritic Soils, Soils and Foundations, 27(2), 1987, pp. 3240.

9. Muntohar, A.S., Influence of Plastic Waste Fibres on the Strength of Lime-ricehusk Ash Stabilized Clay Soil, Civil Engineering Dimension, 11(1), 2009, pp. 32-40.

10. Muntohar, A.S., The Influence of Molding Water Content and Lime Content on the Strength of Stabilized Soil with Lime and Rice Husk Ash, Civil Engineering Dimension, 7(1), 2005, pp. 1-5.

11. Muntohar, A.S., Utilization of Uncontrolled Burnt Rice Husk Ash in Soil Improvement, Civil Engineering Dimension, 4(2), 2002, pp. 100-105.
12. Ibrahim, K.A., Alternative Road Construction Materials using Clay Admixed with Natural Wastes, Bachelor's degree thesis, Universiti Tun Hussein Onn Malaysia, 2007.

13. British Standards Institution (BSI), BS1377: British Standard Methods of Test for Soils for Civil Engineering Purposes, 1990.

14. Chan, C.M., A Laboratory Investigation of Shear Wave Velocity in Stabilized Soft Soils, $\mathrm{PhD}$ thesis, University of Sheffield, 2005.

15. Lee, K.H. and Lee, S., Mechanical Properties of Weakly Bonded Cement Stabilized Kaolin, KSCE Journal of Civil Engineering, 6(4), 2002, pp. 389-398.

16. Bergado, D.T., Anderson, L.R., Miura, N. and Balasubramaniam, A.S., Soft Ground Improvement in Lowland and other Environments, ASCE Press, New York, 1996.

17. Feng, T.W., Lee, J.Y. and Lee, Y.J., Consolidation Behaviour of a Soft Mud Treated with Small Cement Content, Journal of Engineering Geology, 59, 2001, pp. 327-335.

18. Sakr, M.A. and Shahin, M.A., Utilization of Lime for Stabilizing Soft Clay Soil of High Organic Content, Geotechnical and Geological Engineering, 27, 2009, pp. 105-113.

19. Head, K.H., Manual of Soil Laboratory Testing Volume 2: Permeability, Shear Strength and Compressibility Tests, Pentech Press, London, 1982.

20. Rao, S.M. and Shivananda, P., Compressibility Behaviour of Lime-Treated Clay, Geotechnical and Geological Engineering, 23, 2005, pp. 309319. 